\title{
Day-ahead optimal charging/discharging scheduling for electric vehicles in microgrids
}

\author{
Hui Cai ${ }^{1,2^{*}}$, Qiyu Chen ${ }^{3}$, Zhijian Guan ${ }^{2}$ and Junhui Huang ${ }^{2}$
}

\begin{abstract}
Microgrid as an important part of smart grid comprises distributed generators (DGs), adjustable loads, energy storage systems (ESSs) and control units. It can be operated either connected with the external system or islanded with the support of ESSs. While the daily output of DGs strongly depends on the temporal distribution of natural resources such as wind and solar, unregulated electric vehicle (EV) charging demand will deteriorate the unbalance between the daily load curve and generation curve. In this paper, a statistic model is presented to describe daily EV charging/discharging behaviors considering the randomness of the initial state of charge (SOC) of EV batteries. The optimization problem is proposed to obtain the economic operation for the microgrid based on this model. In dayahead scheduling, with the estimated power generation and load demand, the optimal charging/discharging scheduling of EVs during $24 \mathrm{~h}$ is achieved by serial quadratic programming. With the optimal charging/discharging scheduling of EVs, the daily load curve can better track the generation curve. The network loss in grid-connected operation mode and required ESS capacity in islanded operation mode are both decreased.
\end{abstract}

Keywords: Microgrid, Day-ahead schedule, Charging/discharging strategy, Electric vehicle (EV), Serial quadratic programming (SQP)

\section{Introduction}

LARGE-SCALE applications of Microgrids (MGs) and Electric Vehicles (EVs) are the best solutions to overcome the energy crisis and environmental pressure [1]. It is widely accepted that, as an important part of smart grid, microgrid can provide electricity for either local loads in nearby areas by optimally allocating local renewable generators, small or medium traditional power generators, and energy storage systems in islanded operation mode, or a large-scale independent power supply system in grid-connected operation mode [2-5]. Microgrid also acts as a bridge to bring renewable generators and EVs together. Taking into account of uncertain and inflexible output of renewable generators, and random charging demand of EVs, the control strategy for coordinated behaviors of EVs is urgently needed to meet the

\footnotetext{
* Correspondence: 79595050@qq.com

${ }^{1}$ State Grid(Suzhou)City and Energy Research Institute, Suzhou, China

${ }^{2}$ State Grid Jiangsu Economic Research Institute, Nanjing, China

Full list of author information is available at the end of the article
}

autonomous, economic, compatible and reliable requirements of microgrids.

Using the renewable generations to charge the electric vehicles has been accepted as the most economic and environment-friendly method $[6,7]$. In the meantime, EVs have been proposed to provide energy reserves for renewable energy sources due to their storage nature, e. g., for wind energy [8-11], solar energy [12, 13], and geothermal energy [14]. In these literatures, only power or energy balancing equations in the steady state of EVs and renewable generators are applied to describe this provision in transmission grids.

Since EVs can not only act as "load" but also be utilized as "generator" corresponding to charging (G2V) and discharging (V2G) modes. However, many existing literatures have focused on the intelligent charging strategy [15-20] in distribution grids, although discharging management [21-25] has attracted increased attentions in recent years. Smoothing the daily load profile is considered to be the most important issue [15-17, 21, 22] whereas electricity price and economic benefits of EV 
owners are the main motivating factors to obtain load leveling [17]. Some other studies introduced charging/discharging methods to decrease the operation cost [18], and power losses [19, 20, 23]. Several management strategies for EV charging/discharging were established to achieve this objective [24, 25]. In these discharging strategies studied in [21-25], EVs were mostly treated as storage systems while discharging procedure was considered. Strategies for combined charging/discharging with respect to the uncertainties such as travel patterns and initial battery state of charge (SOC), which are more close to the real condition, have not been investigated to date.

Microgrid is different from traditional distribution grid in which energy storage system (ESS) is installed to ensure the reliability with little or no disruption to the loads during islanded operation. EVs can help the islanded system to perform better operation and improve the utilization of renewable energy with their storage capacity and controllability [26-28]. The attentions were closely paid to the voltage and frequency profiles in these papers while the required capacity of ESS and the economic operation of microgrids were not considered, and charging/discharging strategy for EVs has not been investigated in this area.

The main contributions of this paper are as follows.

(1) Combined charging/discharging model is proposed as the extension of the strategy in [15], in which only the scheduling of charging starting time was considered. The discharging standard is defined and two more possible scenarios related to discharging characteristics of EVs are included to describe the charging/ discharging behaviors of EVs at a specified time.

(2) The proposed model is employed in the microgrid to schedule the charging/discharging starting time for a better track of the daily renewable generation curve. Furthermore, network loss and required ESS capacity are decreased, and an economic operation of the microgrid is obtained.

The organization of this paper is as follows. In Section 1 , the optimal charging strategy proposed in [15] is briefly reviewed and the discharging method is extended and presented. Charging and discharging schemes are combined in Section 2 where the assumptions and constraints are also described. Section 3 sets the objective of minimum operation cost in the microgrid where the optimal problem is solved by Serial Quadratic Programming (SQP). The information about the example system is described in Section 4 and in Section 5, four scenarios are simulated. In grid-connected operation, power is exchanged between the microgrid and the upstream distribution system to balance the generation and consumption. Standard deviation of the exchange power is employed to describe the similarity of the generation and load curves. With less standard deviation, the load curve better tracks the generation one, and less exchange power is required. During islanded operation, ESS is applied to maintain the power balance. Under these scenarios, maximum value and standard deviation of the exchange power, network loss in the grid-connected operation and required ESS capacity are compared. In Section 6, it concludes that, unregulated EV charging deteriorates the operation condition, whereas optimal charging/discharging of EV induces many benefits and reduces the operation burdens. Both EV owners and system operators can benefit from the optimal charging/ discharging scheduling proposed in this paper.

\section{Methods}

\subsection{EV optimal charging strategy}

The methodology of optimizing power system demand due to EV charging behavior was presented in [15]. The general EV charging characteristic determined by the $25 \mathrm{kWh}$ lithium-ion battery and four standard charging modes $[29,30]$ was introduced and followed. The diversities among EVs such as the initial battery SOC were considered. The initial SOC of EV batteries always have an element of randomness but the general pattern is influenced by the battery usage. The probability density function (PDF) of the battery SOC after one day travel was expressed as [15]:

$$
h(E ; \mu, \sigma)=\frac{1}{(1-E) \sqrt{2 \pi} \sigma} \times e^{-\left[\ln (1-E)+\ln \left(d_{R}\right)-\mu\right]^{2} /\left(2 \sigma^{2}\right)} 0<E<1
$$

The donations of the variables were explained in [15]. The parameters were obtained according to the case of vehicle travel distance in the U.K. in 2009.

In [15], continuous EV charging power was segmented into discrete predefined time steps over each hour. The discrete power demand $P_{\text {charj }}$ for the $j^{\text {th }}$ period during the charging process and the corresponding discrete SOC of batteries $E_{\text {char } j}$ before the start of charging from each hour were obtained.

Two assumptions were made to simplify model description, i.e., the charging starting time and initial battery SOC were two independent variables, and the power demand at start of the hour lasted for the whole period.

$$
H\left(E_{\text {char }-j}\right)=\int_{E_{\text {char }-j}}^{E_{\text {char } \_(j+1)}} h\left(E_{\text {char }-j} ; \mu, \sigma\right) d E 0<E<1
$$

The mathematical expression of the charging demand at time $l$ for an individual EV battery is given as [15]. 


$$
P_{E V}=\sum_{j=1}^{N_{c}} P_{\text {charj }} \varphi\left(P_{\text {charj }}, l\right)
$$

where $\phi\left(P_{\text {char }}, l\right)$ is the probability of a battery charging under power level $P_{d i s j}$ at specified time $l$, which started charging at time $l$ with a SOC $E_{\text {char } j ;}$ or possible earlier time $k$ with a lower SOC of $E_{\text {char }-(j-(l-k))}$. Its detailed expression was described in [15].

The charging demand of multiple EVs at time $l$ can be obtained from (3) as:

$$
P_{E V S}=\sum_{i=1}^{n} P_{E V}
$$

where $n$ is the number of EVs in the system.

From the example study in [15] which considered the national demand of the U.K. in 2009, it demonstrated that the EV charging demand model considering the random initial SOC of EV batteries was valid to describe the charging behavior of various EVs. The assumptions and the PDF were reasonable to be used in the management of EV charging.

As discharging provides an opportunity to allow EV owners to participate in power regulation and share the benefits from the system operators during the parking periods of their EVs, it is increasingly welcomed by EV owners. In the next section, discharging profile is briefly described and the combined charging/discharging model of EVs considering diversities among initial SOC of the batteries is proposed.

\subsection{Combined EV charging/discharging strategy 2.2.1 EV battery discharging characteristics}

While there is no commonly accepted discharging standard until now, a simple discharging model is utilized in this paper which neglects the impacts from battery temperature, aging and other factors. The batteries discharge with constant power first to support local residential loads and then by constant current in low SOC [31, 32]. In order to protect EV batteries and meet the basic travel requirements of EV owners, the minimum SOC of EV battery during the discharging process is set.

Because fast charging will shorten battery-cycle lifetime and induce voltage flicker in the system [33], repeatedly discharging and charging is uneconomic and harmful to the power quality. Therefore, in this paper, only EV discharging model with low discharging rate is considered, which is labeled as Mode 1 or Mode 2 corresponding to the charging model.

Assuming that the minimum SOC for discharging mode is chosen as $56 \%$ in Mode 1 or $52.8 \%$ in Mode 2, which are higher than the break point where the discharging process changes from constant power discharge

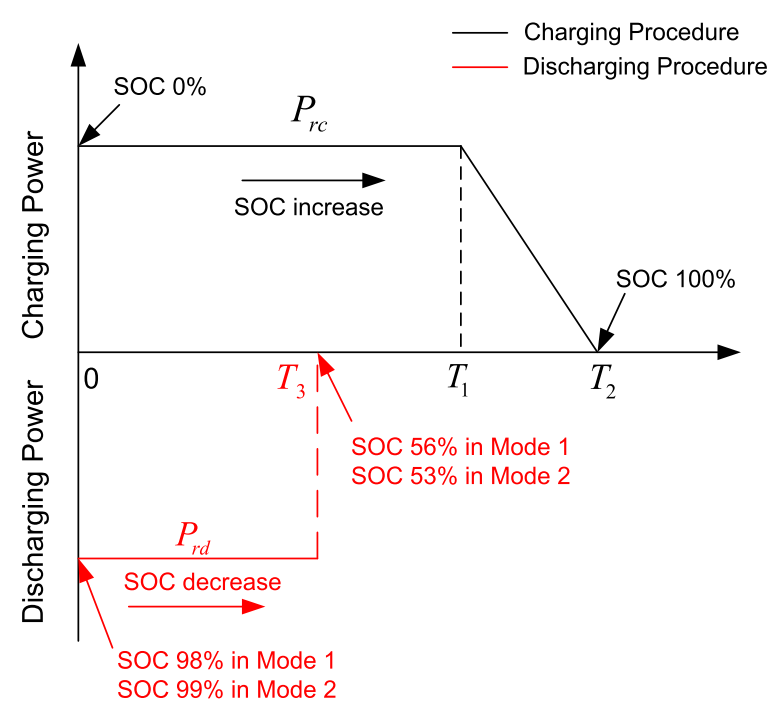

Fig. 1 Generic charging/discharging profile of lithium-ion EV batteries

to constant current discharge, the discharging model can be simply considered as:

$$
P_{\text {dis }}(t)=P_{r d} \quad 0<t \leq T_{3}
$$

where $P_{\text {dis }}(t)$ is the discharging rate at time $t$, and $P_{r d}$ is the rated discharging power, which is normally the same as the rated charging power. $T_{3}$ is the time that guarantees the minimum SOC during discharging process, which has been confirmed as $3 \mathrm{~h}$ in Mode 1 and $2 \mathrm{~h}$ in Mode 2 according to the assumed minimum SOC.

Summarizing the charging and discharging characteristics, a typical profile of lithium-ion EV batteries is presented in Fig. 1. The parameters of EV battery charging/discharging profile are listed in Table 1.

Similar to the discrete analysis method used in continuous $\mathrm{EV}$ charging power, for $\mathrm{EV}$ discharging:

(1) EV discharging power is segmented into predefined time steps over a period of $24 \mathrm{~h}$. The discrete power $P_{d i s j}$ for the $j^{\text {th }}$ period in discharging mode and the corresponding discrete SOC of the batteries $E_{d i s_{-} j}$ before the start of discharging from each hour can be obtained, also taking the PDF of the initial battery SOC into consideration.

Table 1 Parameters of EVs battery charging/discharging profiles

\begin{tabular}{llll}
\hline & Parameters & Mode 1 & Mode 2 \\
\hline Charging & $P_{r c}$ & $3.5 \mathrm{~kW}$ & $6.6 \mathrm{~kW}$ \\
& $T_{1}$ & $6.3 \mathrm{~h}$ & $3.6 \mathrm{~h}$ \\
& $T_{2}$ & $8 \mathrm{~h}$ & $4 \mathrm{~h}$ \\
Discharging & $P_{r d}$ & $3.5 \mathrm{~kW}$ & $6.6 \mathrm{~kW}$ \\
& $T_{3}$ & $3 \mathrm{~h}$ & $2 \mathrm{~h}$ \\
\hline
\end{tabular}


(2) The power supply at the start of the hour will also last for the whole period. The batteries with SOC between $E_{\text {dis_(j-1) }}$ and $E_{\text {dis_j }}$ will have the same discharging behavior in the specified hour, similar to the ones with SOC between $E_{\text {char_ } j}$ and $E_{\text {char }}(j+1)$ having the same charging behavior.

Fully charged EV will not attend the charging/discharging process iteratively in this paper.

\subsubsection{Combined charging/discharging behavior of an EV}

The 4 assumptions for the discussion of combined charging/discharging behavior of an EV are as follows [1, 34-36].

(1) Every EV attends charging/discharging schedule once a day with random initial SOC.

(2) The charging/discharging starting time and initial battery SOC are two independent variables.

(3) During charging process, EV batteries are not to be interrupted until they are fully charged.

(4) In discharging process, the participated EV discharges until SOC of the battery reaches the minimum threshold in Mode 1 or 2 . It will then directly transfer to charging process and reach to full capacity in the following few hours.

(5) The charging/discharging efficiencies of EV battery are both $80 \%$.

The combined charging/discharging behavior of an EV at instant time $l$ can be mathematical expressed as:

$$
\begin{aligned}
P_{E V}= & \frac{\sum_{j=1}^{N_{c}} P_{c h a r j} \varphi\left(P_{c h a r j}, l\right)+\sum_{j=1}^{N_{c}} P_{c h a r j} \phi\left(P_{c h a r j}, l\right)}{\eta_{c h a r}} \\
& -\sum_{j=1}^{N_{c}-N_{d i s}} P_{\text {disj }} \theta\left(P_{\text {dis }}, l\right) \eta_{\text {dis }}
\end{aligned}
$$

where $N_{d}$ is the number of equal time period to consider over one day and $N_{c}$ is the number of period required for a full charging process. $N_{d i s}$ is the specified charging period corresponding to the break point for EV changing from discharging to charging process. They are determined by the time step $T$ for the discretization analysis of the charging/discharging profile. In this paper $N_{d}=24, N_{c}=8 / 4$ and $N_{d i s}=5 / 3$ in both charging mode 1 and $2 . \eta_{\text {chan }} \eta_{\text {dis }}$ are the respective charging and discharging efficiencies of $\mathrm{EV}$ batteries.
Compared with (3), two more scenarios starting from the discharging process $P_{\text {charj }} \phi\left(P_{\text {charj }}, l\right)$ and $P_{\text {dis } j} \theta\left(P_{\text {disj }}, l\right)$ are considered in (6). The proposed new scenarios are presented in details as follows.

Scenario a:

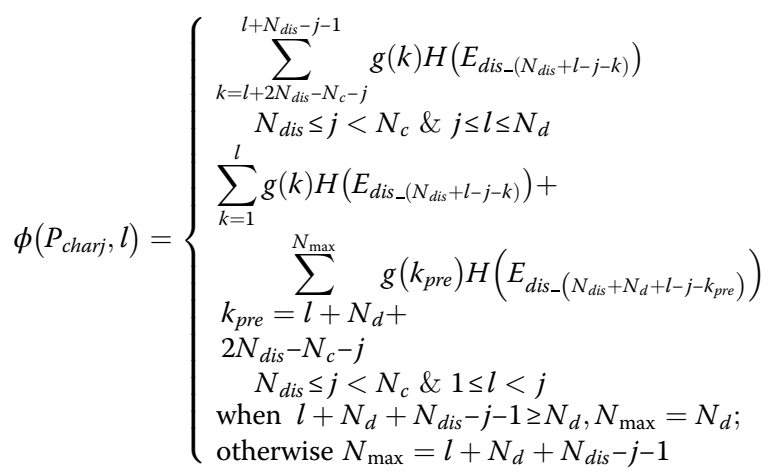

$\phi\left(P_{\text {charj }}, l\right)$ in $(7)$ is the probability of a battery charging under power level $P_{\text {charj }}$ at time $l$, which started discharging from earlier time $k$ with a SOC of $E_{\text {dis_ }}(N d i s+l-j-k)$. Under Assumption (4), the battery participating in discharging will directly charge after the minimum discharging SOC threshold is reached. $g(k)$ is the probability of a discharging process starting at time $k$ and $H\left(E_{\text {dis }}\right.$ $(N d i s+l-j-k)$ is the probability of an initial battery SOC from which the EV charges under power level $P_{\text {charj }}$ at time $l$. In this scenario, the effect caused by the discharging process starting from the previous night is considered in the second part.

Scenario b:

$$
\theta\left(P_{d i s j}, l\right)=\left\{\begin{array}{l}
\sum_{k=l+j-\left(N_{c}-N_{d i s}\right)}^{l} g(k) H\left(E_{\text {dis }-(j+l-k)}\right) \\
1 \leq j \leq N_{c}-N_{d i s} \& N_{c}-N_{d i s} \leq l \leq N_{d} \\
\sum_{k=N_{\min }}^{l} g(k) H\left(E_{d i s_{-}(j+l-k)}\right)+ \\
\sum_{k=l+N_{d}+j-\left(N_{c}-N_{\text {dis }}\right)}^{N_{d}} g(k) H\left(E_{\text {dis_- }\left(j+l+N_{d}-k\right)}\right) \\
1 \leq j \leq N_{c}-N_{d i s} \& 1<N_{c}-N_{\text {dis }} \\
\text { when } l+j>4, N_{\min }=l ; \text { otherwise } N_{\min }=1
\end{array}\right.
$$

$\theta\left(P_{\text {disj }}, l\right)$ in $(8)$ is the probability of a battery discharging under power level $P_{\text {disj }}$ at time $l$, which started discharging at time $l$ with a SOC of $E_{d i s j}$ or possible earlier time $k$ with a higher SOC of $E_{\text {dis_ }(j+(l-k))} \cdot g(k)$ is the probability of a discharging process starting at time $k$ and $H\left(E_{\text {dis_ }(j+l-k)}\right)$ is the probability of an initial battery SOC from which the EV discharges under power level $P_{d i s j}$ at time $l$. In this scenario, the effect caused by the 


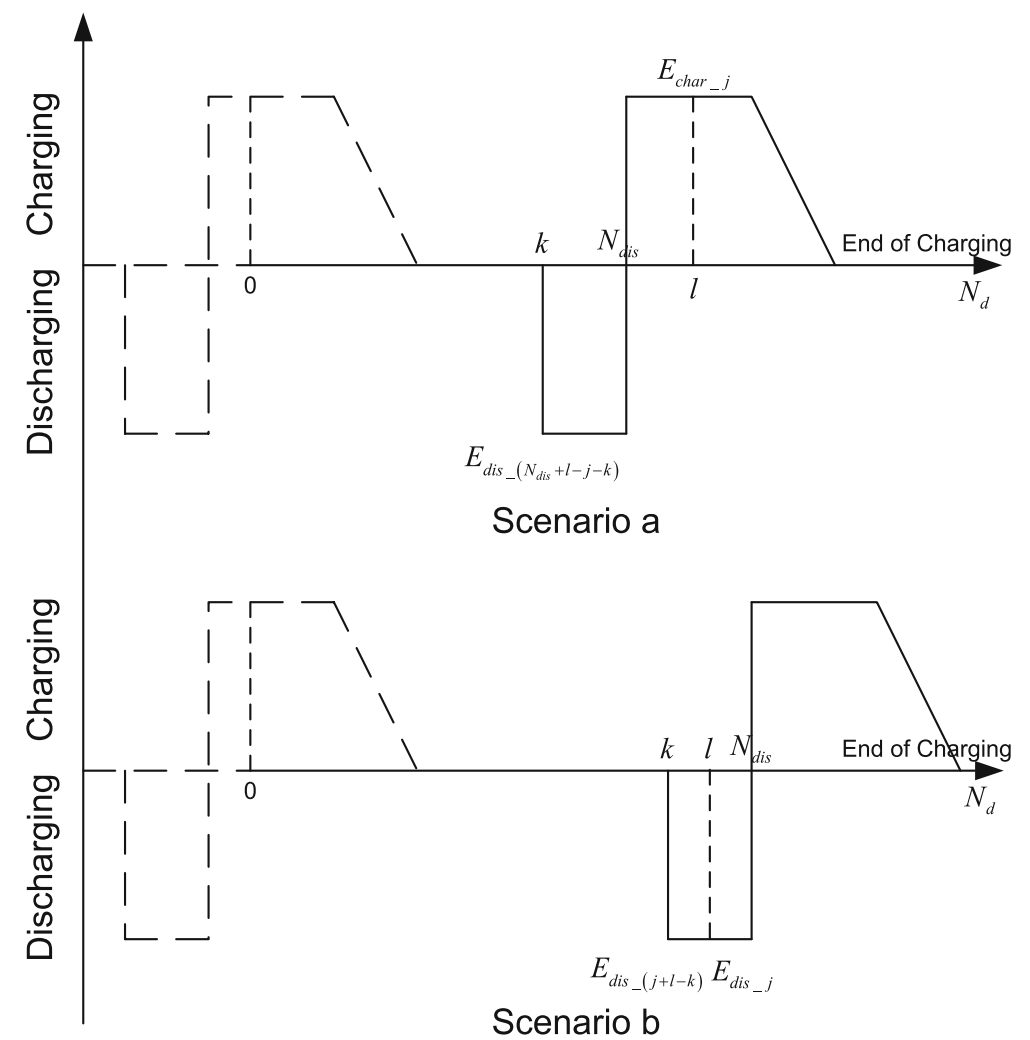

Fig. 2 Schematics of the two scenarios starting from discharging process of a single EV battery

process starting from the previous night is also considered in the second part.

The schematics of the two scenarios are shown in Fig. 2.

\subsubsection{Charging/discharging behavior of multiple EVs}

The charging/discharging behavior of multiple EVs is the direct sum of the individual EVs. Thus, the charging/discharging behavior of multiple EVs at instant time $l$ can also be obtained according to (4).

\subsubsection{Microgrid operation optimization}

There are many variable sources in the microgrid, for example distributed generators (DGs) and EVs. Peak power produced by the DGs normally cannot match the peak load around 19:00-21:00, as the peak of solar power generation is usually at noon and wind power in the mid-night. Unregulated EV charging will increase the unbalance between power generation and consumption. In this paper, the optimal function is established to reduce this unbalance. The daily operation cost of the microgrid is minimized by scheduling the EV charging/discharging starting time during $24 \mathrm{~h}$ under the power flow constraints.

\subsubsection{Standard power flow constraints}

The power flow in the microgrid has these constraints [34]:

$$
P_{i, l}=\sum_{j=1}^{n}\left(\left|Y_{i, j}\right| \cdot\left|V_{i, l}\right| \cdot\left|V_{j, l}\right| \cdot \cos \left(\theta_{i, j}+\delta_{j, l}-\delta_{i, l}\right)\right)
$$

$$
Q_{i, l}=-\sum_{j=1}^{n}\left(\left|Y_{i, j}\right| \cdot\left|V_{i, l}\right| \cdot\left|V_{j, l}\right| \cdot \sin \left(\theta_{i, j}+\delta_{j, l}-\delta_{i, l}\right)\right)
$$

where the subscripts $i$ and $l$ denote at bus $i$ in hour $l$.

The voltage is limited as:

$$
0.9 \leq\left|V_{i, l}\right| \leq 1.1 \text { p.u. }
$$

The current limitations in the cables are:

$$
I_{i, j, l} \leq I_{i, j, \max }
$$

where the subscripts $i$ and $j$ denote two terminal buses of the cable.

The transformer capacity limitations is:

$$
\sqrt{P_{D i, l}^{2}+Q_{D i, l}^{2}} \leq S_{i}^{\max }
$$

where subscript $D$ denotes the load.

The network loss per hour is calculated as: 


$$
P_{\text {Loss }}=\frac{1}{2} \sum_{j=1}^{n}\left(\sum_{i=1}^{n}\left(\begin{array}{l}
G_{i, j} \cdot\left(\left|V_{i, l}\right|^{2}+\left|V_{j, l}\right|^{2}\right. \\
\left.-2 \cdot\left|V_{i, l}\right| \cdot\left|V_{j, l}\right| \cdot \cos \left(\delta_{j, l}-\delta_{i, l}\right)\right)
\end{array}\right)\right)
$$

\subsubsection{Optimal function and objective}

The optimal function is established mainly to minimize the exchange power between microgrid and upstream distribution system, but also partially to reduce the network loss in the microgrid. By following this optimal function, the load curve including charging/discharging behaviors of EVs can better track the power generation curve. The required capacity of ESS in the islanded operation mode is also reduced due to the better match between the generation and consumption curves.

The objective is to minimize the result of (15) by optimal scheduling the hourly charging/discharging EV numbers in a day for lowest required ESS capacity and network loss.

$$
\begin{array}{r}
\min z=\min \left(\operatorname{Var}\left(W_{\text {Tie-line }} P_{\text {Tie-line }}\right)+W_{\text {Loss }} P_{\text {Loss }}\right) \\
=\min \left(\begin{array}{l}
\frac{W_{\text {Tie-line }}}{N_{d}} \sum_{l=1}^{N_{d}}\left(P_{\text {Tie-line }}(l)-P_{\text {Tie-line }}\right)^{2} \\
+\frac{W_{\text {Loss }}}{N_{d}} \sum_{l=1}^{N_{d}}\left(P_{\text {Loss }}(l)\right)^{2}
\end{array}\right) \\
\text { s.t. } \sum_{l=1}^{24}(f(l)+g(l))=1, f(l) \geq 0, g(l) \geq 0 \quad \sum_{l=1}^{24} g(l) \leq g_{\max }
\end{array}
$$

In (15) $z$ is the optimal function. $P_{\text {Loss }}$ is obtained from the power flow solution in every optimal searching iteration and $P_{\text {Load }}(l)$ represents the non-EV load demand at time $l$. The exchange power $P_{\text {Tie-line }}(l)$ at time $l$ is equal to the unbalance between the total consumption $P_{\text {Load }}(l)$ $+P_{E V s}(l)+P_{\text {Loss }}(l)$ and total generation $P_{G e n}(l) . f(l)$ and $g(l)$ are the decision variables which are the percentages of EVs that start charging and discharging at time $l$. $P_{\text {Tie-line }}$ is the mean value of the exchange power. $W_{\text {Tie- }}$ line, $W_{\text {Loss }}$ are the weighting factors for the optimal problem. In this paper $W_{\text {Tie-line }}=0.8$, and $W_{\text {Loss }}=0.2$.

\subsubsection{Sequential quadratic programming (SQP)}

The optimal function can be solved by sequential quadratic programming (SQP). It takes $z$ (optimal function) and $f(l), g(l)$ for $l=1,2, \ldots, 24$ (decision variables) as inputs, finds the local minimum of $z$ that satisfies the constraints by varying the values of $f(l)$ and $g(l)$, and then outputs the corresponding optimal values.

\section{Results}

\subsection{System information and assumptions in an example microgrid \\ 3.1.1 System information}

To investigate the impacts of EVs to the operation cost of microgrids, an example system is given in Fig. 3.

In this paper, the constant output of gas turbine is utilized to cover the base load. Analysis is focused on the optimal charging/discharging scheduling of EVs in day-ahead market. Gap between the real and estimate renewable generations and consumptions can be eliminated by the fast response ESSs though their influence is not discussed here.

Tables 2 and 3 present the information about buses and feeder impedances in the example system. The continuous load curve, gas turbine, wind farm and photovoltaic output power are also segmented into

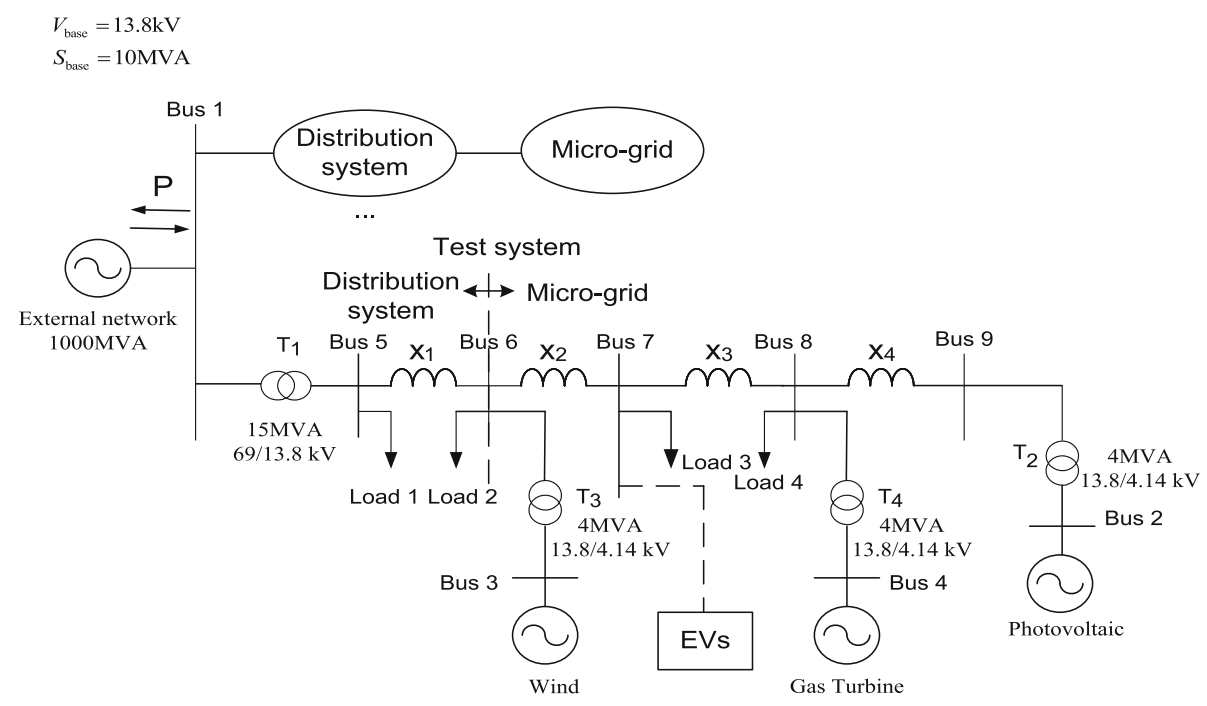

Fig. 3 Microgrid example system 
Table 2 Bus information of the example system

\begin{tabular}{lllllll}
\hline Bus No. & Voltage & & & Load & Bus Type \\
\cline { 2 - 3 } & V (p.u.) & $\delta(\mathrm{deg})$ & & V (p.u.) & $\delta(\mathrm{deg})$ & \\
\hline 1 & 1.03 & 0 & 0 & 0 & Slack Bus \\
2 & 1.01 & 0 & 0 & 0 & PV Bus \\
3 & 1.03 & 0 & 0 & 0 & PV Bus \\
4 & 1.01 & 0 & 0 & 0 & PV Bus \\
5 & 1 & 0 & Fig. 4 & - & PQ Bus \\
6 & 1 & 0 & Fig. 4 & - & PQ Bus \\
7 & 1 & 0 & Fig. 4 & - & PQ Bus \\
8 & 1 & 0 & Fig. 4 & - & PQ Bus \\
9 & 1 & 0 & 0 & 0 & PQ Bus \\
\hline
\end{tabular}

discrete predefined time steps over a period of $24 \mathrm{~h}$, as well as EV charging/discharging power demand or generation.

The load and generation curves can be obtained through one-day-ahead estimation as shown in Figs. 4 and 5. The parameters are given in [37-39].

\subsubsection{Assumptions in the example microgrid}

In the example microgrid, the following assumptions are made.

(1) There are 200 EVs connected to the microgrid. The aggregation units (AU) of EV charging points can efficiently manage EV charging and discharging processes to the grid, and in this paper the AU is connected at Bus $7[1,9,15]$.

(2) One Doubly Fed Induction Generator (DFIG) with 1.5 MW capacity is newly installed to meet the charging demand of EVs. The daily estimated output of the DFIG is shown in Fig. 6 and the detailed parameters are given in [37-39]. The capacity of transformer $T_{3}$ is extended to $6 \mathrm{MW}$ accordingly.

(3) Battery storage system and diesel generator are the two components of ESS. The generated energy is stored into the battery during power surplus and is

Table 3 Line information of the example system

\begin{tabular}{|c|c|c|c|c|c|}
\hline \multirow[t]{2}{*}{ Line No. } & \multicolumn{2}{|c|}{ Bus No. } & \multicolumn{2}{|c|}{ Impedance (p.u.) } & \multirow[t]{2}{*}{ Tap Ratio } \\
\hline & From & To & $R$ & $x$ & \\
\hline 1 & 1 & 5 & 0 & 0.01667 & 1 \\
\hline 2 & 2 & 9 & 0 & 0.01667 & 1 \\
\hline 3 & 3 & 6 & 0 & 0.01667 & 1 \\
\hline 4 & 4 & 8 & 0 & 0.01667 & 1 \\
\hline 5 & 5 & 6 & 0.003 & 0.025 & - \\
\hline 6 & 6 & 7 & 0.006 & 0.055 & - \\
\hline 7 & 7 & 8 & 0.006 & 0.055 & - \\
\hline 8 & 8 & 9 & 0.003 & 0.025 & 1 \\
\hline
\end{tabular}

extracted when the generation is insufficient. The diesel generator is used once the energy stored in the battery is reduced to its minimum threshold. Different connection buses of ESS can affect the required ESS capacity but are not considered in this paper.

(4) In order to protect the batteries, the minimum threshold for the battery storage system during discharging is $0.5 \mathrm{MWh}$. When the remaining energy in the system reaches $0.5 \mathrm{MWh}$, it is out of operation until additional energy is re-stored.

(5) The required capacity of ESS is calculated considering the need for the microgrid to be in islanded operation for the whole day.

(6) Thirty percent EVs are volunteered to participate in discharging procedure.

\subsection{Case study}

The charging/discharging schedule of EVs during $24 \mathrm{~h}$, the daily exchange power between the microgrid and upstream distribution system, the network loss and required ESS capacity are compared under the following four cases:

Case A: System without EVs;

Case B: Under direct charging strategy by Mode 1;

Case C: Under optimal charging strategy by Mode 1;

Case D: Under optimal charging/discharging strategy by Mode 1 .

\subsubsection{Charging/discharging schedule of EVs}

In Case A, no EV exists in the system and no scheduling for EV needs to arrange.

In Case B, EVs are charged instantaneously after the end of their trips. Each of $15 \%$ are assumed to charge at 9:00 and 23:00 respectively, $40 \%$ at $19: 00,20 \%$ at 20:00 and $0.5 \%$ at each of the rest $20 \mathrm{~h}$. The schedule under direct charging strategy generally shows periodic variation over a day.

In Case $\mathrm{C}$, the optimal charging strategy is obtained from (15). Only the first scenario in (6), which denotes to the charging process, is considered.

In Case D, the optimal charging/discharging strategy is obtained from (15). Three scenarios in (6), including the charging and discharging processes, are all considered. According to the randomness of initial SOC, the vehicles scheduled to discharge have small possibility of SOC lower than the minimum threshold. These vehicles will not attend the charging process and they are individually charged in the following hours. In this case, while the V2G participated level is $29 \%$, the percentage of these vehicles is even smaller than 5\%. Thus, their effects are insignificant and thus are neglected in this paper.

The charging/discharging schedules for EVs in $24 \mathrm{~h}$ under the four cases are shown in Fig. 7. 


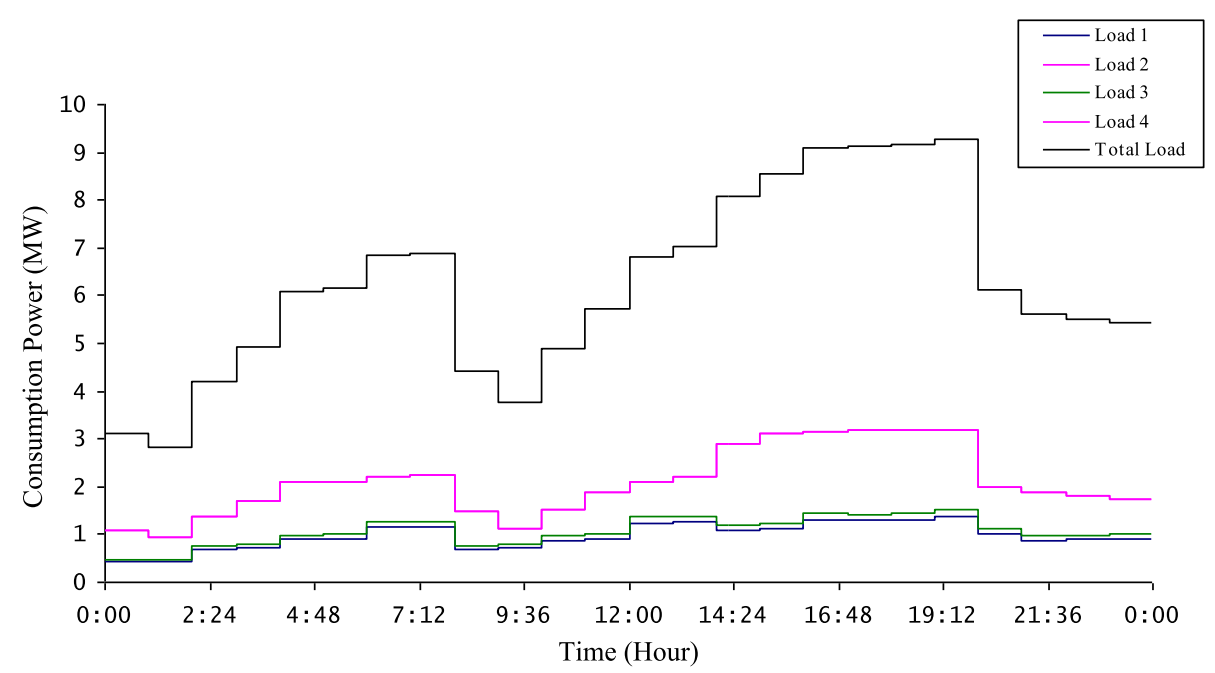

Fig. 4 Daily load curves of the microgrid example system

\subsubsection{Exchange power between microgrid and upstream distribution system}

The charging demands/discharging supplies of EVs in $24 \mathrm{~h}$ under the four cases are shown in Fig. 8 , and the exchange power in $24 \mathrm{~h}$ under the four cases are shown in Fig. 9.

From Figs. 7, 8 \& 9, the followings can be observed.

In Case $\mathrm{A}$, the line connecting the microgrid and upstream distribution system needs be designed to carry the 3.8192 MW maximum exchange power. The average value is $-0.4111 \mathrm{MW}$ and the standard deviation is $1.8083 \mathrm{MW}$, which designates for the unbalance level between the daily load and generation curves.

In Case B, the charging demand of EVs under direct charging strategy is mainly around 9:00, 19:00 and 23:00 which coincide with the daily peak load. EVs' charging increases the load burden in the microgrid during 19: 00-20:00. The line needs be designed to carry the 6 . 2759 MW maximum exchange power, representing a 64. $32 \%$ increase compared with the result obtained in Case A. The average value is $-0.1624 \mathrm{MW}$. The energy generated by the newly installed 1.5 MW wind generator during $24 \mathrm{~h}$ is sufficient for the charging demand of 200 EVs with small energy surplus. The standard deviation is $2.3560 \mathrm{MW}$, which is an increase of $30.29 \%$ compared to that in Case A.

In Case $\mathrm{C}$, the charging processes for the primary EVs are concentrated at night in which the wind power is also high. Around 50 EVs utilized as secondary vehicles are scheduled to start charging at 8:00 [40]. The line need be designed to carry the 2 . 6517 MW maximum exchange power, a $57.74 \%$

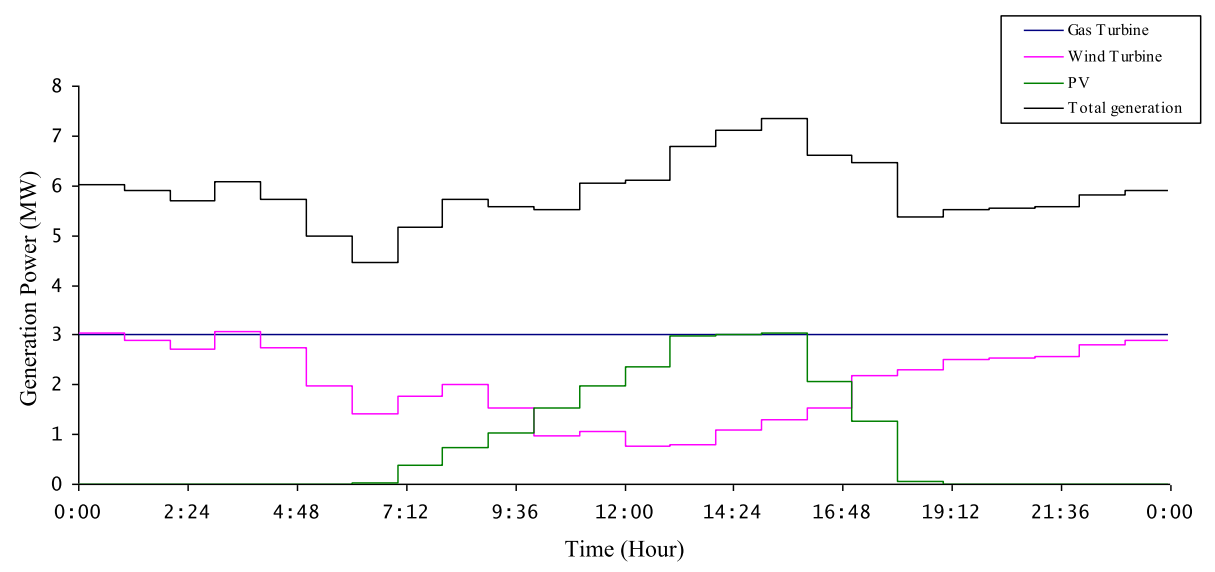

Fig. 5 Daily generation curves of microgrid example system 


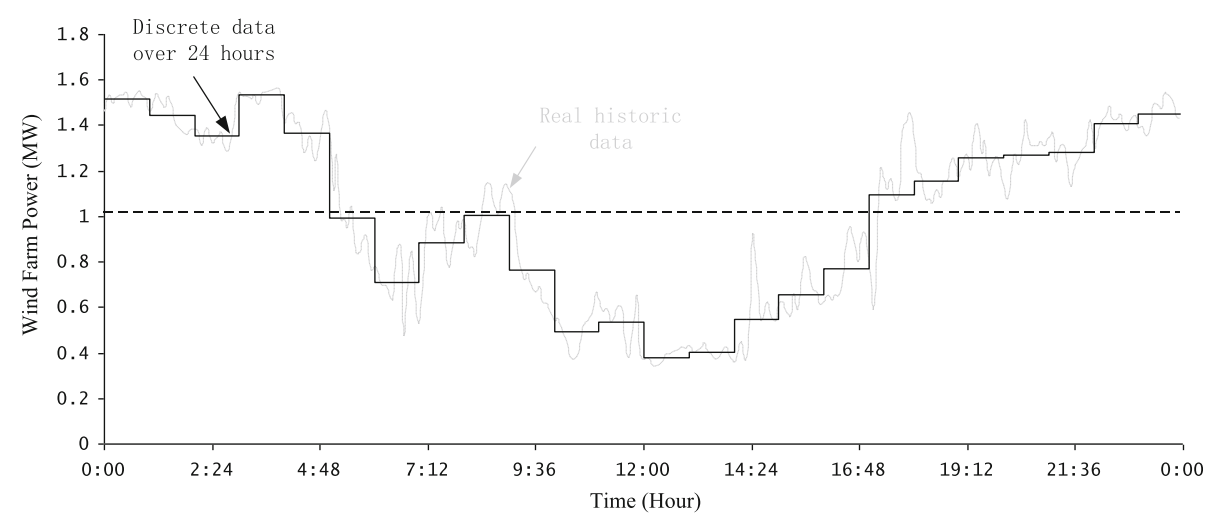

Fig. 6 Daily output power of 1.5 MW DFIG

decrease compared with that in Case B. The average value is $-0.1413 \mathrm{MW}$ and the standard deviation is $1.3465 \mathrm{MW}$, a decrease of $42.85 \%$.

In Case D, the primary EVs are also started charging at night whereas $15 \%$ secondary vehicles start charging at 8:00. Around $29 \%$ vehicles start discharging during 16: 00-18:00 to support the grid during the peak load period. The line needs designed to carry the $1.8041 \mathrm{MW}$ maximum exchange power, a $31.96 \%$ decrease compared with the result obtained in Case $C$. The average value is $-0.1312 \mathrm{MW}$ and the standard deviation is reduced by $32.41 \%$ to $0.9101 \mathrm{MW}$.

\subsubsection{Network loss}

The network losses in the microgrid in $24 \mathrm{~h}$ under the four cases are compared in Fig. 10.

From Fig. 10, the network losses under four cases can be obtained respectively based on (16) as:

$$
W_{\text {Loss }}=\sum_{l=1}^{24}\left(P_{\text {Loss }} \cdot T\right)
$$

In Case A, the power loss is $1.29 \mathrm{MWh}$, whereas in Case B, it is increased by $36.2 \%$ to $1.6072 \mathrm{MWh}$. In Case $\mathrm{C}$, the power loss is reduced to $1.2515 \mathrm{MWh}$

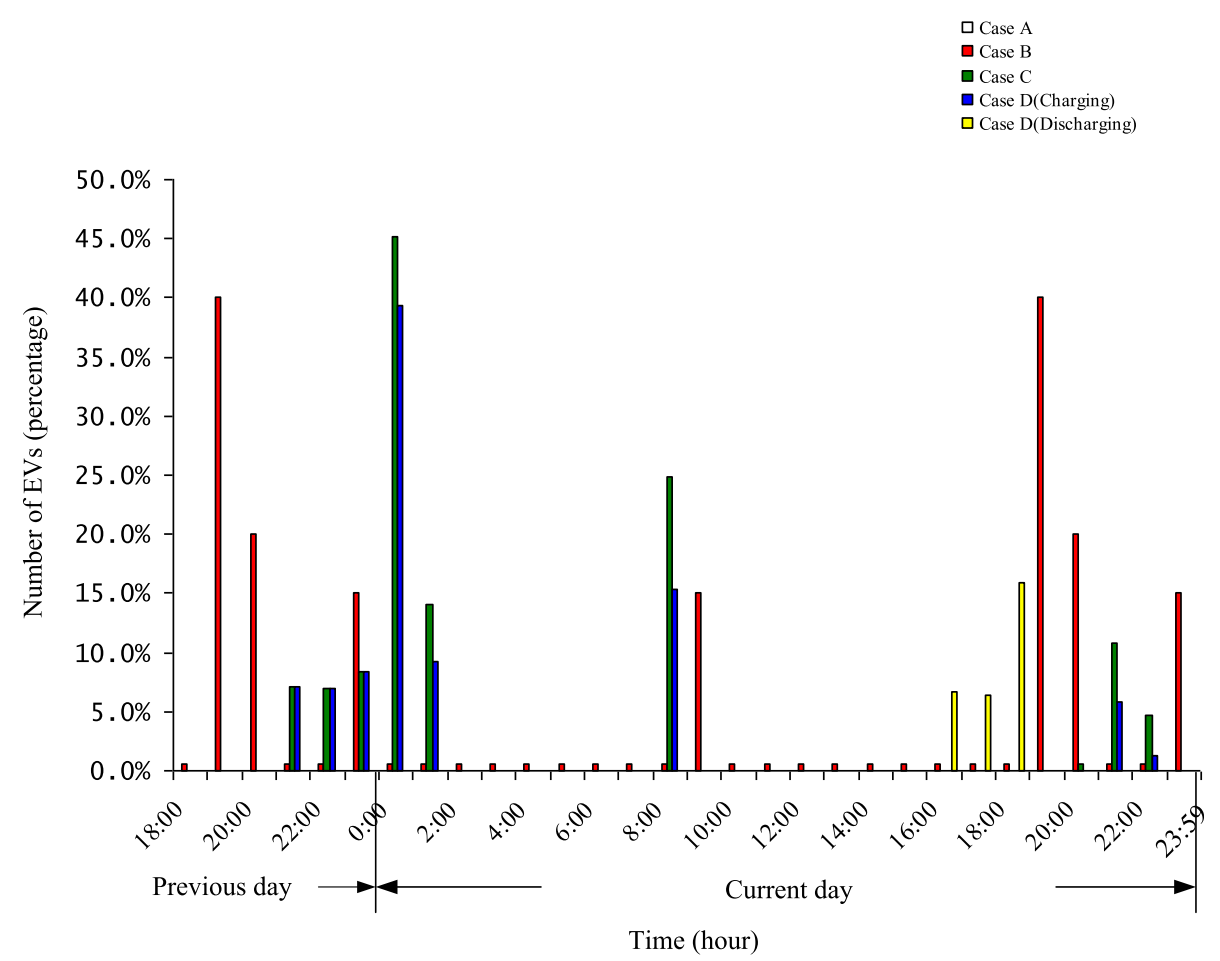

Fig. 7 Hourly charging/discharging schedules under four cases 


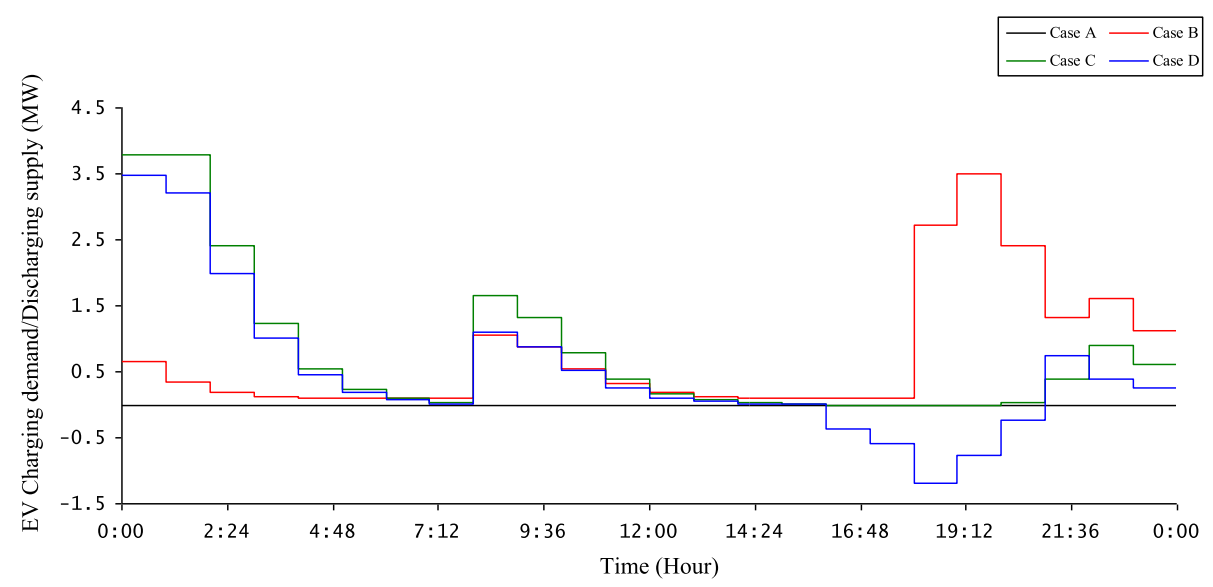

Fig. 8 Hourly charging demands/discharging supplies of EVs under four cases (Positive power denotes the charging demand of EVs. Negative power expresses the discharging supply of EVs)

representing a $22.1 \%$ decrease compared with that in Case B. The power loss is further reduced in Case D to $0.8986 \mathrm{MWh}$, a $28.2 \%$ reduction compared to that in Case C.

\subsubsection{Required ESS capacity}

Based on the given Assumption (3)-(5), the required ESS capacities in $24 \mathrm{~h}$ under the four cases are shown in Figs. 11 and 12.

From Figs. 11 and 12, the followings can be seen.

In Case A, the battery system with the maximum energy capacity around $9.0 \mathrm{MWh}$ is charged during the night. It discharges to $0.5 \mathrm{MWh}$ at $16: 00$ and is out of operation until additional energy is re-stored from 22:00. The diesel generator with the maximum energy capacity around 11MWh replaces the battery during 16:00-22:00.

In Case $B$, while the peak wind power generation and charging demand of EVs appear at different time periods, more power generation is in surplus at night whereas more load required to be fed during the peak load period around 19:00-22:00. The required maximum energy capacity of the battery system is around $15 \mathrm{MWh}$ to store the surplus wind energy. Diesel generator with the maximum energy capacity around $5 \mathrm{MWh}$ is also required to balance the load, EV charging demand and generation during 19:00-22:00.

In Case $\mathrm{C}$, optimal charging of EVs can effectively use the surplus wind energy at night. It helps to reduce the required capacity of battery storage system and consequently, only a battery system with the maximum energy capacity around $4.5 \mathrm{MWh}$ is required. During the peak load period, the capacity of diesel generator increases while less energy is re-stored at night, and thus the maximum energy capacity around 7.5MWh is required.

In Case D, with the support of contracted discharging EVs, only $1.5 \mathrm{MWh}$ capacity of diesel generator is

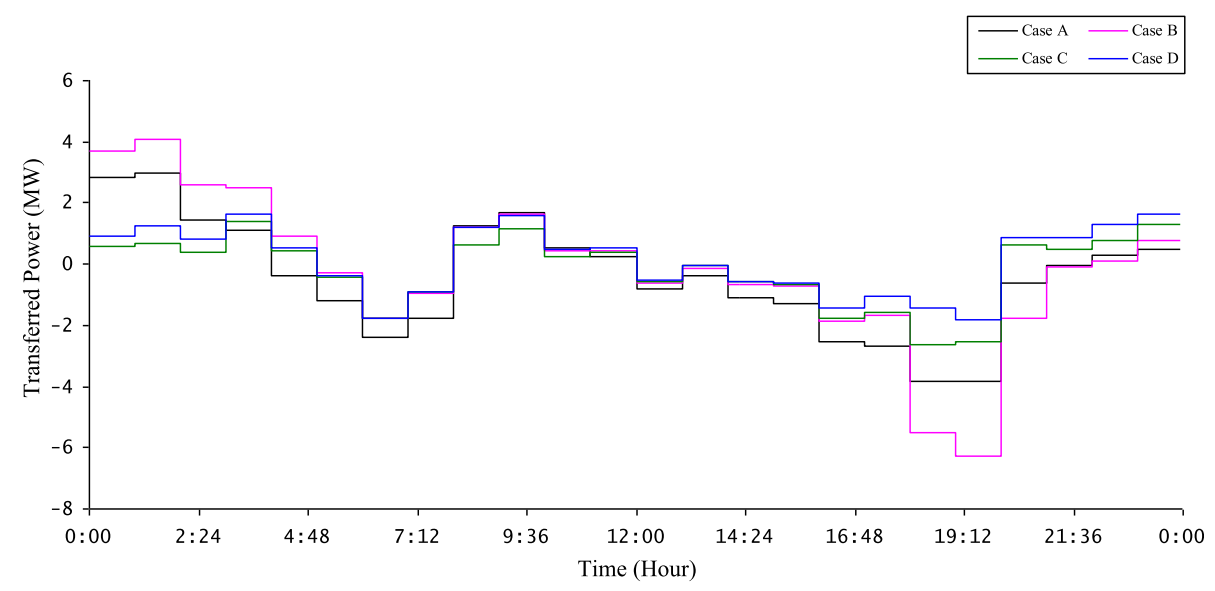

Fig. 9 Hourly exchange power under four cases (Positive power denotes the power delivering from the microgrid to external system. Negative power expresses the power sending from the external system into microgrid) 


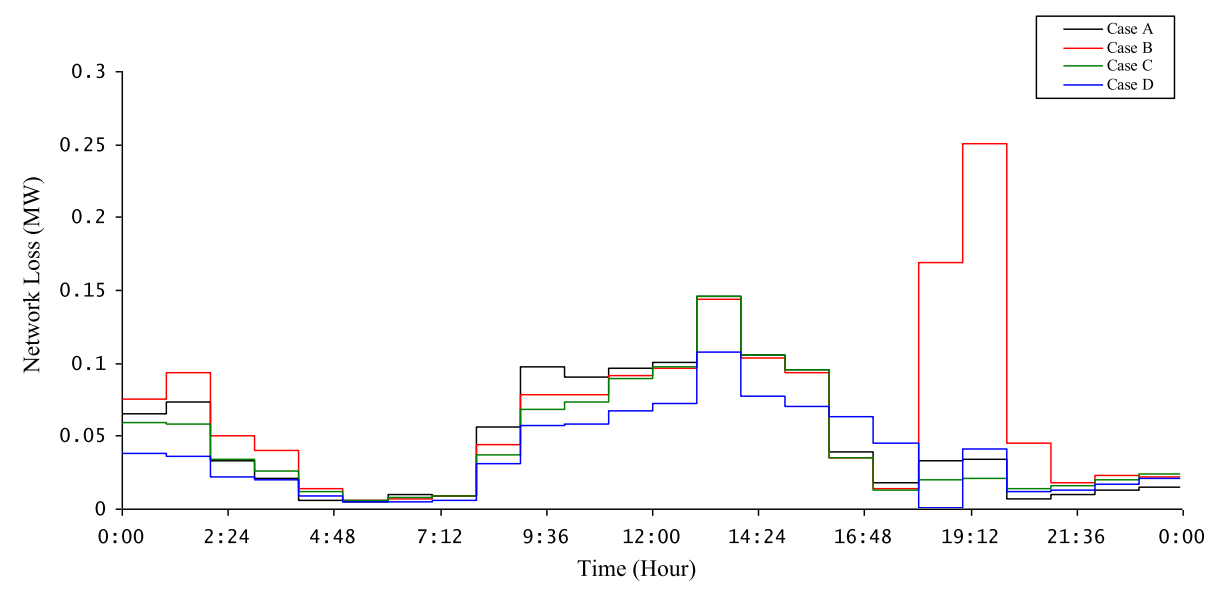

Fig. 10 Hourly network losses under four cases

required at 18:00, and around $4.5 \mathrm{MWh}$ energy capacity of battery system is also required.

\subsubsection{Optimal discharging number under different volunteered EVs}

Discharging (V2G) is the most promising opportunity to let the EV owners participate in power regulation and share the benefits from the system operators. Assuming that increasing EVs volunteer into this procedure, optimal discharging-participate number obtaining from (15) with increased $g_{\max }$ is shown in Fig. 13.

Because of the constraints in the assumptions that every vehicle attends charging or discharging only once a day and the charging period for the V2G-participated vehicles is directly after their discharging, the optimal number of discharging vehicles is set as 74 although every vehicle has volunteered for V2G process. Too many EVs discharging to support the peak load can lead to reduced charging capacity for the utilization of surplus wind energy at night.

EV owners can be invited and contracted to participate in the discharging process starting from specified hours through an internet application or SMS messages. The system operators choose the first contracted EVs according to the optimal schedules.

\subsubsection{Case E: Under optimal charging/discharging strategy by mode 2}

The charging/discharging schedule for EVs by Mode 2 is obtained based on (15). EVs finish their charging/ discharging behaviors with smaller time scale and higher charging/discharging power, which provide more flexibility in the optimal scheduling and lead

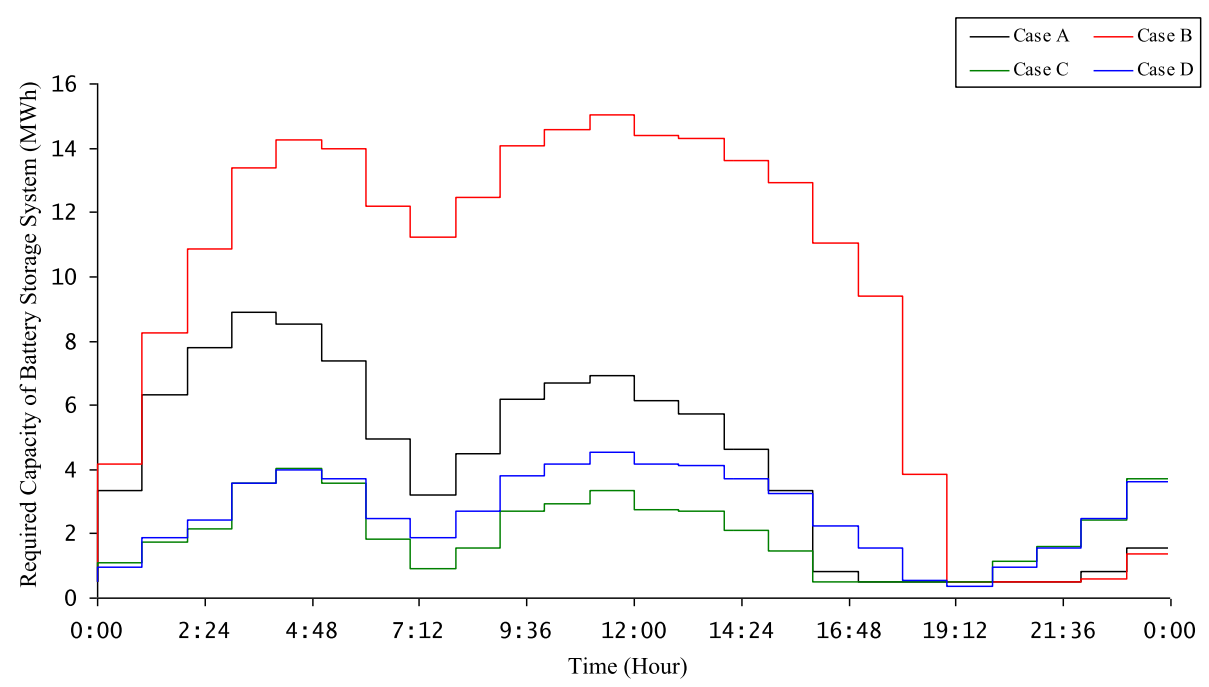

Fig. 11 Required capacities of battery storage system under four cases 


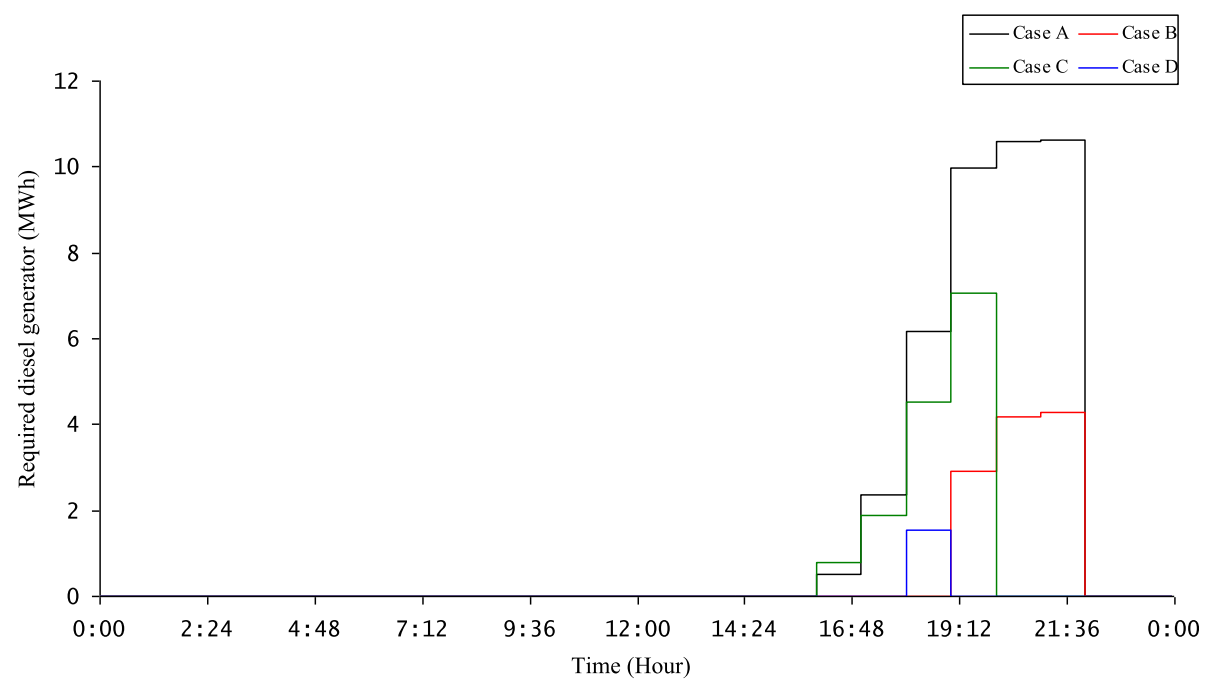

Fig. 12 Required capacities of diesel generator under four cases

to improved results over Mode 1 with longer charging/discharging profile.

The primary EVs are also concentrated to start charging at night. Seven percent secondary vehicles start charging at 8:00, and 20\% vehicles during 16:00-18:00 to support the grid during the peak load period. The line connecting the microgrid and upstream distribution system needs be designed to carry 1.2750 MW maximum exchange power, which is a $29.33 \%$ reduction compared with the result obtained in Case D. The average value is $-0.1398 \mathrm{MW}$ and the standard deviation is $0.7225 \mathrm{MW}$, a decrease of $20.61 \%$. The total network loss over $24 \mathrm{~h}$ is reduced by $27.14 \%$ compared with the result in Case D to $0.6547 \mathrm{MWh}$. The required capacity of ESS is also reduced in this case. Only $0.8 \mathrm{MWh}$ capacity of diesel generator is required at 18:00 while the required maximum energy capacity of the battery system is around 3.3MWh.

\section{Discussions}

The comparisons of the exchange power, the network losses and required ESS capacities under the five different cases are listed in Table 4.

From Table 4, the followings can be observed.

(1) In the grid-connected operation, unregulated charging of EVs increases the maximum exchange power via the line connecting the microgrid and upstream distribution system, and the network loss in the microgrid. The standard deviation of exchange power is increased which denotes high unbalance between the generation and consumption curves and more exchange power required to maintain the power balance.

During the islanded operation of the microgrid, more battery storage system is required to store the surplus

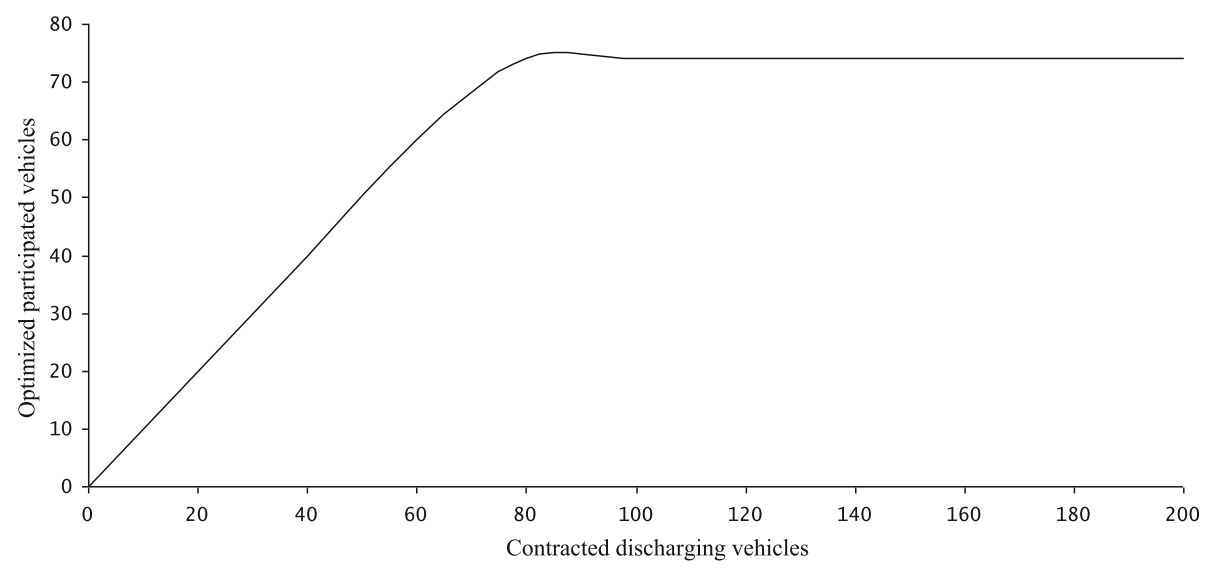

Fig. 13 Optimal participated number under different volunteered EVs 
Table 4 Comparisons of results obtained in five cases

\begin{tabular}{llllll}
\hline & $\begin{array}{l}\text { Max-delivered } \\
\text { Power (MW) }\end{array}$ & $\begin{array}{l}\text { Standard deviation of } \\
\text { delivered Power (MW) }\end{array}$ & $\begin{array}{l}\text { bkNetwork } \\
\text { loss (MWh) }\end{array}$ & \multicolumn{2}{l}{ ESS Energy Capacity (MWh) } \\
\cline { 5 - 6 } & 3.8192 & 1.8083 & 1.29 & Battery storage system & Diesel generator \\
\hline A & 6.2759 & 2.3560 & 1.6072 & 15.0 & 11.0 \\
B & 2.6517 & 1.3465 & 1.2515 & 4.5 & 5.0 \\
D & 1.8041 & 0.9101 & 0.8986 & 4.5 & 7.5 \\
E & 1.2750 & 0.7225 & 0.6547 & 3.3 & 1.5 \\
\hline
\end{tabular}

(Case A: System without EVs; Case B: Under direct charging strategy by Mode 1; Case C: Under optimal charging strategy by Mode 1; Case D: Under optimal charging/discharging strategy by Mode 1. Case E: Under optimal charging/discharging strategy by Mode 2)

wind energy at night. Diesel generator together with the stored energy is utilized to meet the peak loads.

(2) In the grid-connected operation, both the maximum exchange power and network loss are decreased under the optimal charging strategy. The standard deviation of exchange power is also decreased indicating a better match between generation and consumption curves and less exchange power required to maintain the power balance.

During the islanded operation of the microgrid, while the load curves with charging demand of EVs can better match the generation curve at night, less energy is stored in the battery system and thus, more energy is required from diesel generator to support the peak load.

(3) In the grid-connected operation, the maximum exchange power, the network loss and the standard deviation of exchange power are further decreased under the optimal discharging strategy.

During the islanded operation of the microgrid, less diesel generation capacity is required to meet the peak load with the help from discharging behaviors of EVs. The load curve including the charging/discharging of EVs can track the generation curves well not only at night but also during the peak load period.

(4) According to the charging and discharging model, even with $100 \%$ EVs volunteering to participate in discharging process, only the optimal number of EVs are contracted to participate in the specified hours. When the price paid to the electricity from EV batteries is considerable but is still less than the saving from reduced network loss and ESS back-up capacity, both the EV owners and system operators benefit from the optimal scheduling.

(5) Optimal charging/discharging scheduling of EVs by higher power level leads to further decreased maximum exchange power and network loss in the microgrid. Additional reduction of the standard deviation of exchange power is obtained, and so as the capacities of battery storage system and diesel generator required during islanded operation. More flexibility is provided in scheduling with shorter charging/discharging profile.

\section{Conclusions}

Microgrids and EVs are inevitably becoming the future developing trends. While renewable generators supply main power in microgrid and they are strongly dependent on the natural resources, ESS needs be utilized to balance the gap between daily load and generation curves during islanded operation. Charging/ discharging behaviors of EVs can be used to reduce the peak demand and increase the minimum load curve, in order to better match the generation curve. Better scheduled charging/discharging of EVs can improve the operation condition of microgrid, whereas unregulated EV charging induces many challenges.

In this paper, a method with combined charging/discharging behaviors of EVs with respect to the uncertainties of initial battery SOC and travel pattern is proposed. The optimal scheduling of charging/discharging starting time of EVs is obtained based on this method, in order to reduce the operation cost of the microgrid. The results from the example system verify the effectiveness of the proposed method. Under the optimal charging/discharging strategy of EVs, load curve including the charging/ discharging of EVs can track the generation curve well not only at night but also during the peak load period. Maximum and aggregate exchange power through the line connecting the microgrid and upstream distribution system, as well as network losses are decreased. The required capacities of battery storage system and diesel generator are also reduced. Higher charging/discharging power levels can further lead to increased benefit for both the EV owners and system operators.

\section{Funding}

The research of this paper was supported by National Natural Science Foundation of China (No. 51577032), Natural Science Foundation of Jiangsu Province (No. BK20160679), EPSRC UK-China joint research consortium (EP/ F061242/1), Science bridge award (EP/G042594/1). 


\section{Availability of data and materials}

Data sharing not applicable to this article as no datasets were generated or analyzed during the current study.

\section{Authors' contributions}

Dr. $\mathrm{HC}$ and Dr. QC contributed to the proposed EV charging/discharging strategy and the case study. ZG and JH contributed to the database and case study. All authors read and approved the final manuscript.

\section{Authors' information}

Dr. H. Cai is currently working in State Grid(Suzhou)City and Energy Research Institute. His research interests include energy strategy and electricity market. His email address is 79595050@qq.com.

Dr. Q.Y. Chen is working in China Electric Power Research Institute, Beijing. His research interests include energy strategy and electricity market. His email address is caihui300@hotmail.com.

Z.J. Guan is working in State Grid Jiangsu Economic Research Institute, Nanjing. His research interests include distribution power system planning. His email address is zhijianguan@js.sgcc.com.

J.H. Huang is working in State Grid Jiangsu Economic Research Institute, Nanjing. His research interests include trasmission power system planning. His email address is junhuihuang@js.sgcc.com.

Dr. H. Cai is the corresponding author of this paper. His postal address is No. 251, Zhongshan Road, Nanjing, 210008.

\section{Competing interests}

The authors declare that they have no competing interests.

\section{Author details}

'State Grid(Suzhou)City and Energy Research Institute, Suzhou, China. ${ }^{2}$ State Grid Jiangsu Economic Research Institute, Nanjing, China. ${ }^{3}$ China Electric Power Research Institute, Beijing, China.

Received: 3 February 2018 Accepted: 23 March 2018

Published online: 06 April 2018

\section{References}

1. Liu, Z. Y. Electric power and energy in China [M]. China Electric Power Press, China (in Chinese), pp.45-50, 79-86.

2. Hatziargyriou, N. D., Dimes, A., Tsikalakis, A. G., et al. (2005). Management of Micro-grids in market environment [C]. International Conference on Future Power Systems, 1-7.

3. Lasseter, R. H., \& Paigi, P. (2002). Micro-grid: A conceptual solution [C]. IEEE 35th Annual Power Electronics Specialists Conference PESC, 4285-4290.

4. European Commission (2007). Strategic research agenda for Europe's Electricity Networks of the future [OL]. Available: http://www.sm.artgrids.eu/ documents/sra/sra_finalversion.pdf.

5. Govardhan, M. D., \& Roy, R. (2011). A review on key issues of micro-grid [C]. Proceedings of the 2011 IEEE PES ISGT India, 322-327.

6. Kempton, W., \& Tomić, J. (2005). Vehicle-to-grid power fundamentals: Calculating capacity and net revenue [J]. J Power Sources, 144(1), 268-279.

7. Pasaoglu, G., Honselaar, M., \& Thiel, C. (2012). Potential vehicle fleet $\mathrm{CO}_{2}$ reductions and cost implications for various vehicle technology deployment scenarios in Europe [J]. Energy Policy, 40, 404-421.

8. Zhao, J. H., Wen, F. S., Dong, Z. Y., Xue, Y. S., \& Wong, K. P. (2012). Optimal dispatch of electric vehicles and wind power using enhanced particle swarm optimization [J]. IEEE Transactions on Industrial Informatics, 8(4), 889-899.

9. Yu, D. Y., Liu, Y. H., Li, J. G., \& Liu, Y. H. (2010). The potential benefit of controlled PEV charging on the wind power integration [C]. International Conference on Power System Technology (POWERCON), 1-5.

10. Kempton, W., \& Dhanju, A. (2006). Electric vehicles with V2G: Storage for large-scale wind power [J]. Windtech International, 2(2), 18-21.

11. Liu, C., Wang, J. H., Botterud, A., Zhou, Y., \& Vyas, A. (2012). Assessment of impacts of PHEV charging patterns on wind-thermal scheduling by stochastic unit commitment [J]. IEEE Transactions on Smart Grid, 3(2), 675-683.

12. Kempton, W., \& Tomić, J. (2005). Vehicle-to-grid power implementation: From stabilizing the grid to supporting large-scale renewable energy [J]. J Power Sources, 144(1), 280-294.

13. Su, W. C., Rahimi-Eichi, H., Zeng, W., \& Chow, M. Y. (2012). A survey on the electrification of transportation in a smart grid environment[J]. IEEE Transactions on Industrial Informatics, 8(1), 1-10.
14. Camus, C., \& Farias, T. (2012). The electric vehicles as a mean to reduce $\mathrm{CO}_{2}$ emissions and energy costs in isolated regions. The São Miguel (Azores) case study []]. Energy Policy, 43, 153-165.

15. Zhang, P., Qian, K., Zhou, C., Stewart, B. G., \& Hepburn, D. M. (2012). A methodology for optimization of power systems demand due to electric vehicle charging load [J]. IEEE Transactions on Power Systems, 27(3), 1628-1636.

16. Qian, K., Zhou, C., Allan, M., \& Yuan, Y. (2011). Modeling of load demand due to EV battery charging in distribution systems. IEEE Transactions on Power Systems, 26(2), 802-810.

17. Fan, Z. (2012). A distributed demand response algorithm and its application to PHEV charging in smart grids []]. IEEE Transactions on Smart Grid, 3(3), 1280-1290.

18. Rotering, N., \& llic, M. (2011). Optimal charge control of plug-in hybrid electric vehicles in deregulated electricity markets. IEEE Transactions on Power Systems, 26(3), 1021-1029.

19. Masoum, A. S., Deilami, S., Moses, P. S., Masoum, M. A. S., \& Abu-Siada, A. (2011). Smart load management of plug-in electric vehicles in distribution and residential networks with charging stations for peak shaving and loss minimization considering voltage regulation [J]. IET Generation, Transmission \& Distribution, 5(8), 877-888.

20. Sortomme, E., \& El-Sharkawi, M. A. (2011). Optimal charging strategies for unidirectional vehicle-to-grid [J]. IEEE Transactions on Smart Grid, 2(1), 131-138.

21. Lassila, J., Haakana, J., Tikka, V., \& Partanen, J. (2012). Methodology to analyze the economic effects of electric cars as energy storages [J]. IEEE Transactions on Smart Grid, 3(1), 506-516.

22. A. Nebel, C. Krüger, and F. Merten. Vehicle to grid and demand side management - An assessment of different strategies for the integration of electric vehicles [C]. IET Conference on Renewable Power Generation (RPG 2011), pp. 1-6, Edinburgh, the U.K., 2011.

23. Dallinger, D., Krampe, D., \& Wietschel, M. (2011). Vehicle-to-grid regulation reserves based on a dynamic simulation of mobility behavior [J]. IEEE Transactions on Smart Grid, 2(2), 302-313.

24. Sánchez-Martín, P., Sánchez, G., \& Morales-España, G. (2012). Direct load control decision model for aggregated EV charging points. IEEE Transactions on Power Systems, 27(3), 1577-1584.

25. He, Y. F., Venkatesh, B., \& Guan, L. (2012). Optimal scheduling for charging and discharging of electric vehicles [J]. IEEE Transactions on Smart Grid, 3(3), 1095-1105.

26. J. A. P. Lopes, P. M. R. Almeida, and F. J. Soares. Using vehicle-to-grid to maximize the integration of intermittent renewable energy resources in islanded electric grids [C]. Proc. Int. Conf. Clean Electr. Power Renewable Energy Resources Impact, pp. 290-295, Capri, Italy, 2009.

27. Lopes, J. A. P., Soares, F. J., \& Almeida, P. M. R. (2011). Integration of electric vehicles in the electric power system [J]. Proceedings of the IEEE, 99(1), 168-183.

28. J. A. P. Lopes, C. L. Moreira, and F. O. Resende. Micro-grids black start and islanded operation [C]. Proc. 15th Power Syst. Comput. Conf., pp. 1-7, Liege, Belgium, 2005.

29. Bruno, S., \& Jurgen, G. (2010). Lithium batteries: Status, prospects and future [J]. Journal of Power Sources, 195(9), 2419-2430.

30. Majeau-Bettez, G., Hawkins, T. R., \& Stroemman, A. H. (2011). Life-cycle environmental assessment of lithium-ion and nickel metal hydride batteries for plug-in hybrid and battery electric vehicles [J]. Environmental Science \& Technology, 45(10), 4548-4554.

31. M. Duvall. Battery evaluation for plug-in hybrid electric vehicles [C]. IEEE Proc. vehicle power and propulsion conf., pp. 338-343, 2005.

32. Q.Q. Cao. Research on Modeling and Access System Analysis of V2G [M] Master Dissertation, Beijing: Beijing Jiaotong University, 2011 (in Chinese).

33. K. Yunus, H.Z. de la Parra and M. Reza. Distribution Grid Impact of Plug-in Electric Vehicles Charging at Fast Charging Stations Using Stochastic Charging Model [C]. Proceedings of the 2011-14th European Conference on EPE, pp.1-11, 2011.

34. G.K. Venayagamoorthy. SmartParks for Short Term Power flow Control in Smart Grids [C]. IEEE International Electric Vehicle Conference (IEVC) 2012, pp. $1-6,2012$.

35. Mitra, P., \& Venayagamoorthy, G. K. (2011). SmartPark as a virtual STATCOM [J]. IEEE Transaction on Smart Grid, 2(3), 445-455.

36. P. Mitra and G.K Venayagamoorthy. Intelligent Coordinated Control of a Wind Farm and Distributed SmartParks [C]. IEEE Industry Application Society Annual Meeting (IAS) 2010, pp. 1-8, 2010.

37. Steen, D., Tuan, L. A., Carlson, O., \& Bertling, L. (2012). Assessment of electric vehicle charging scenarios based on demographical data [J]. IEEE Transaction on Smart Grid, 3(3), 1457-1468. 
38. U. Kwhannet, N. Sinsuphun, U. Leeton and T. Kulworawanichpong. Impact of Energy Storage in Micro-grid Systems with DGs [C]. 2010 International Conference on Power System Technology, pp.1-6, 2010.

39. P. Kundur. Power System Stability and Control [M]. The EPRI Power System Engineering Series, McGraw-Hill,USA, pp.180-240.

40. L. Zhao, P. Awater, A. Schaefer, C. Breuer and A. Moser. Scenario-Based Evaluation on the Impacts of Electric Vehicle on the Municipal Energy Supply Systems [C]. 2011 IEEE PES General Meeting, pp.1-8, 2011.

\section{Submit your manuscript to a SpringerOpen ${ }^{\mathcal{O}}$ journal and benefit from:}

- Convenient online submission

- Rigorous peer review

- Open access: articles freely available online

- High visibility within the field

- Retaining the copyright to your article

Submit your next manuscript at $\gg$ springeropen.com 